\title{
Pulse Energy Modulation in a Three-Switch Buck-Boost Inverter for Distributed Generation Systems
}

\author{
Yonggao Zhang, Yanli Gao, Yi Qu and Wanqing Liu \\ School of Electrical and Electronic Engineering, East China JiaoTong University \\ Nanchang, Jiangxi, P.R.China, 330013 \\ ygzhang@ecjtu.jx.cn
}

\begin{abstract}
Single-phase grid-connected inverters play an important role in small distributed generation $(D G)$ systems. This paper illustrates the circuit configuration and operation principle of a novel single-phase, single-stage, three-switch, fly-back, buck-boost inverter. The equivalent circuits associated with the four operation modes are established for the charging and discharging process. The inverter can operate in both continuous conduction mode (CCM) and discontinuous conduction mode (DCM). Most importantly, a new pulse generation method called pulse energy modulation (PEM) is proposed and applied to the three-switch buck-boost inverter in this paper. PEM signals for controlling the power switches are generated by meeting the output energy demand in each switching period with the stored energy in the coupled fly-back inductors. The duty ratio of PEM is thus determined by the energy demand and dc input voltage. The efficiency of the inverter used PEM is analyzed. A $400 \mathrm{~W}$ experimental prototype is built in the laboratory to verify the operation of the proposed pulse energy modulation method. The inverter controller employs DSP dsPIC33FJ64MC506 for controlling, detecting and protecting functions. Experimental results have shown that PEM provides a new modulation mechanism for controlling the three-switch buck-boost inverter to inject a sinusoidal current into the grid under a wide range of operating conditions.
\end{abstract}

Keywords: Distributed generation; pulse energy modulation; buck-boost inverter

\section{Introduction}

With the increasing concern about the fossil fuel reserves and greenhouse gas emissions, renewable energy sources, such as wind energy, solar energy, biomass, and geothermal energy, have attracted more and more attention for electricity generation. This presents a significant opportunity for the development of distributed generation (DG) systems. Grid-connected inverters play an important part in the distributed generation systems for grid interconnection and system optimization [1-2]. For a small DG system, an inverter with compact, economical and efficient design is highly desired. Typical two-stage buck-boost inverters can handle a wide variation of input dc voltage, but their complicated structure leads to a costly solution for small DG systems. Many single-stage buck-boost inverters [3-6] have been proposed to accomplish the voltage regulation and dc-ac conversion in a simplified form for small DG applications.

Kusakawa et. al., [3] proposed a six-switch, single-phase, full-bridge, buck-boost inverter which was implemented by charging the energy-storage inductor from different directions in each half cycle. The compactness of this transformer-less topology makes it appropriate for an ac module in PV systems. Jain and Agarwal investigated a four-switch, transformerless, buck-boost inverter in [4]. This inverter has the advantages of simplicity, compactness, low cost and simple control, but suffers from low voltage gain, low efficiency and double grounding [5]. A four-switch buck-boost inverter with dual fly-back 
transformers was proposed by Kjær and Blaabjerg [4]. An important merit of this inverter is the galvanic isolation provided by the two bidirectional high frequency transformers. However, the use of two transformers suggests an expensive and bulky solution. Kasa et. al., [7] then proposed an isolated, fly-back, half-bridge, buck-boost inverter which was a modified version of the dual transformer topology [6]. This inverter has only three power devices and one isolation transformer, however, is applicable to low power systems due to the limitation on the primary inductance of the center-tapped transformer.

In their efforts to search for an innovative solution of inverter topology, Liuchen Chang et. al., [8] considered the component count, cost and size along with pulse generation techniques, and proposed a single-phase, single-stage, fly-back, buck-boost inverter with three switching devices. In [9], the authors illustrated the working principles of three-switch buck-boost inverter and simulated the operation for this inverter with SPWM by PSIM. The results prove its feasibility for dc-ac conversion in PV applications.

This paper emphasis on the implement and tests of this three-switch buck-boost inverter and studies its pulse modulation techniques. Many pulse modulation techniques have been developed and tested for DG inverters. The objectives of a modulation technique are to generate the switching signals for power devices so as to produce high-quality output voltage/current with wide range of source/load conditions, to minimize switching losses and to improve inverter efficiency. There have been two main types of switching signal generation methods in the power converters: Pulse Width Modulation (PWM) and Pulse Frequency Modulation (PFM). PFM is a method of encoding information where the instantaneous frequency of a pulse train carries the signal's information [10]. It is more efficient at light loads because the switching frequency and associated switching losses are scaled down with a reduced load current. It is mostly used in discontinuous conduction mode (DCM) for dc-dc converters [10]. Pulse width modulation methods generate switching pulses with certain algorithms based on reference and carrier voltage waveforms, and are widely used because they have controllable output magnitude and frequency with predefined harmonic spectrum [11-16]. The most common PWM modulation technique for inverters is Sinusoidal Pulse-Width Modulation (SPWM), which generates a sinusoidal ac output voltage/current from a dc input source [11]. Hysteresis PWM (HPWM) technique is also widely used for generating ac current in inverters with the advantage of easy implementation, quick response, and insensitive to load parameter variations [12]. In [13], HPWM was applied to a single-stage buck-boost inverter. Pulse area modulation (PAM) [14] and non-linear pulse width modulation (NPWM) [15] were proposed to reduce harmonic distortion created by power fluctuation at twice grid frequency in a current-source single-phase inverter. In [16] a single-phase grid-connected inverter is proposed using Sequential Magnetizing Modulation (SMM) and Time-Shared Magnetizing Modulation (TMM) to create an active power decoupling with the dc voltage source to reduce power fluctuation at twice grid frequency for single-phase inverters.

Both PFM and PWM generate the switching signals based on the assumption of constant dc link voltage, it produces output distortions if the dc input voltage and/or load condition changes rapidly. In [17] a new PWM technique, in which the reference waveform was obtained by equating the input energy and output energy during a high frequency switching cycle, was present. However, only the DCM operation was studied and the modulation technique belongs to PWM technique. The pulse width was calculated by comparing the reference waveform and the modulation waveform.

In this paper, the authors present a new pulse generation principle called pulse energy modulation (PEM) as an alternative inverter control method for the proposed grid-connected, single-phase, fly-back, buck-boost inverter with three switches [18]. PEM is a modulation scheme employing the output energy demand to generate switching signals of inverters. At each switching period, the output energy demand of inverter is calculated to control the stored energy in inductors, and then delivered to the output of a single-phase 
grid. The pulse width is calculated directly through the demanded energy and dc input voltage. It can be used in the condition of rapidly changing dc input voltage.

The remainder of this paper is organized as follows: Section II introduces the circuit configuration and operation principles of the three-switch fly-back buck-boost inverter. The equivalent circuits associated with the charging and discharging processes are established. The discontinuous conduction mode (DCM) and continuous conduction mode (CCM) are discussed. Section III describes the principle of pulse energy modulation, duty ratio, and efficiency. Section IV presents the design of a laboratory $400 \mathrm{~W}$ three-switch buck-boost inverter. Section V reports the experimental results of PEM applied to the buck-boost inverter. Finally, Section VI provides the conclusion.

\section{Circuit Configuration and Operation Principle}

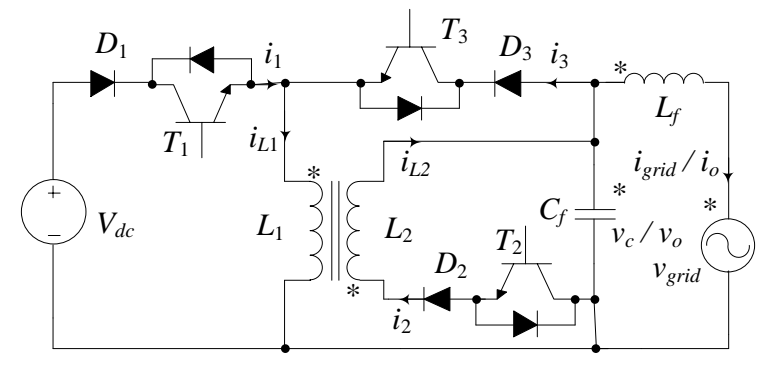

Figure 1. Three-Switch Buck-Boost Inverter with a Coupled fly-Back Inductor

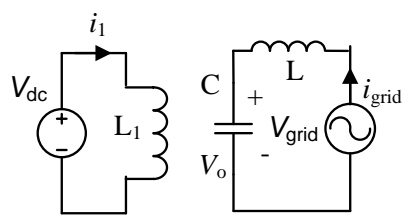

(a) Mode 1
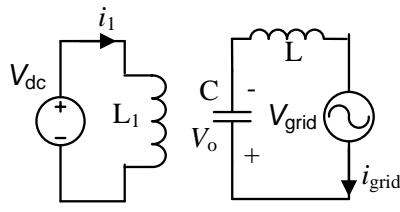

(c) Mode 3

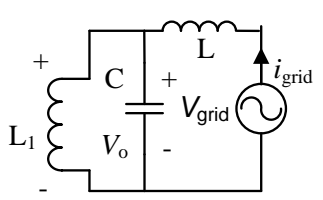

(b) Mode 2

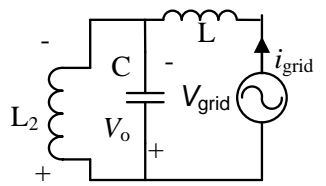

(d) Mode 4

\section{Figure 2. Equivalent Circuits of Four} Operation Modes

Figure 1, is the circuit configuration of the novel three-switch fly-back inverter presented in this paper. This inverter consists of three switches, T1, T2 and T3, three diodes, D1, D2, and D3, an output capacitor $C_{f}$, a filter inductor Lf, and a fly-back inductor with two coupled coils $L_{1}$ and $L_{2}$. The two coupled coils have the same turns and equal inductance, $L_{1}=L_{2}=L_{B B}$.

The fly-back inductor is used to transfer energy from the dc side to the utility grid. Diodes D1, D2 and D3 prevent the reverse current flow from the grid to the dc source. Switch T1 controls the stored energy in the fly-back inductor through a charge and discharge process. The other two switches (T2 and T3) are connected to the grid and are switched on alternately to discharge the fly-back inductor energy to the grid when switch $\mathrm{T} 1$ is in off state. Capacitor $C_{f}$ and inductor $L_{\mathrm{f}}$ filter out the high frequency current components, allowing a smooth current feeding into the grid.

The fundamental principle of this buck-boost inverter is characterized by the charging and discharging operations in the positive half cycle and in the negative half cycle of the grid voltage. The operation principles of the inverter can be described by four operation modes, with their equivalent circuits shown in Figure 2.

\subsection{Mode 1: Charging in the Positive Half Cycle}

In this mode, switch T1 is turned on and switches T2 and T3 are turned off. Neglecting inductor copper losses and switching losses, the equivalent circuit of Mode 1 is shown in Figure 2 (a). The primary inductor $L_{l}\left(L_{B B}\right)$ is charged to store energy from the dc source, and the output current igrid is provided by the discharge of capacitor $v_{\mathrm{c}}$. The equations of this mode can be expressed by: 


$$
\begin{aligned}
& i_{1}=i_{L 1} ; \quad L_{B B} \frac{d i_{L 1}}{d t}=V_{d c} ; \quad i_{L 2}=0 ; \\
& L_{f} \frac{d i_{\text {grid }}}{d t}=v_{c}-v_{\text {grid }} ; \quad C_{f} \frac{d v_{c}}{d t}=-i_{\text {grid }}
\end{aligned}
$$

where $i_{L 1}$ is the current in fly-back inductor $L_{1}, i_{L 2}$ is the current in fly-back inductor $L_{2}$, $V_{d c}$ is the dc input source voltage, $v_{\text {grid }}$ is the grid voltage, and $v_{c}$ is the output capacitor voltage.

\subsection{Mode 2: Discharging in the Positive Half Cycle}

Figure 2 (b), shows the equivalent circuit of Mode 2. Assuming the perfect coupling of the two fly-back inductor coils, $i_{L 1}$ drops to zero suddenly and $i_{L 2}$ reaches to the initial value of $i_{L 1}$ at the time of switching. The secondary inductor $L_{2}\left(L_{B B}\right)$ is discharged to inject energy into the ac grid through the filter inductor and output capacitor. We have:

$$
\begin{gathered}
i_{1}=0 ; \quad i_{L 1}=0 ; \quad L_{B B} \frac{d i_{L 2}}{d t}=v_{c} ; \\
L_{f} \frac{d i_{\text {grid }}}{d t}=v_{c}-v_{\text {grid }} ; \quad C_{f} \frac{d v_{c}}{d t}=i_{L 2}-i_{\text {grid }}
\end{gathered}
$$

\subsection{Mode 3: Charging in the Negative Half Cycle}

The only difference between Mode 3 and Mode 1 is that in Mode 3, the grid is in the negative half cycle. The equivalent circuit of Mode 3 is shown in Figure 2 (c). In this mode, the capacitor voltage $v_{c}$, the grid voltage $v_{\text {grid }}$ and the output current $i_{\text {grid }}$ are opposite as compared to those in Mode1. The equations of this mode are the same as those in Mode 3.

\subsection{Mode 4: Discharging in the Negative Half Cycle}

Figure 2 (d), shows the equivalent circuit of Mode 4. The dc input source is disconnected from the ac grid and the storage energy in fly-back inductor $L_{1}$ is discharged to the ac grid. We have:

$$
\begin{gathered}
i_{1}=0 ; \quad L_{B B} \frac{d i_{L 1}}{d t}=v_{c} ; \quad i_{L 2}=0 ; \\
L_{f} \frac{d i_{\text {grid }}}{d t}=v_{c}-v_{\text {grid }} ; \quad C_{f} \frac{d v_{c}}{d t}=-i_{L 1}-i_{\text {grid }}
\end{gathered}
$$

The currents in the fly-back inductor and the switching device and the voltage of capacitor during the charging and discharging periods in whole cycle of the grid voltage are shown in Figure 3. Mode 1 and Mode 3 are named as the charging modes, and Mode 2 and Mode 4 as discharging modes. Since only one switch is turned on in each operation mode and a fly-back inductor is always connected to the charging/discharging circuit, the dead time for preventing two switches from shooting-through is unnecessary. 


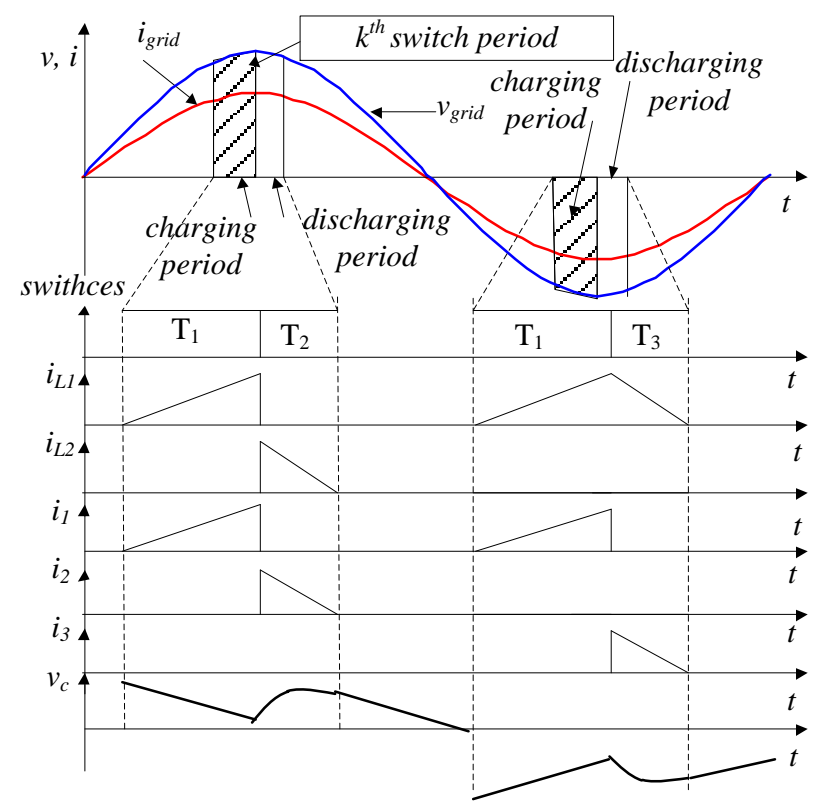

Figure 3. The Current in Fly-Back Inductors and Switchers During Charging Period and Discharging Period in the Positive and Negative Cycle of the Grid Voltage

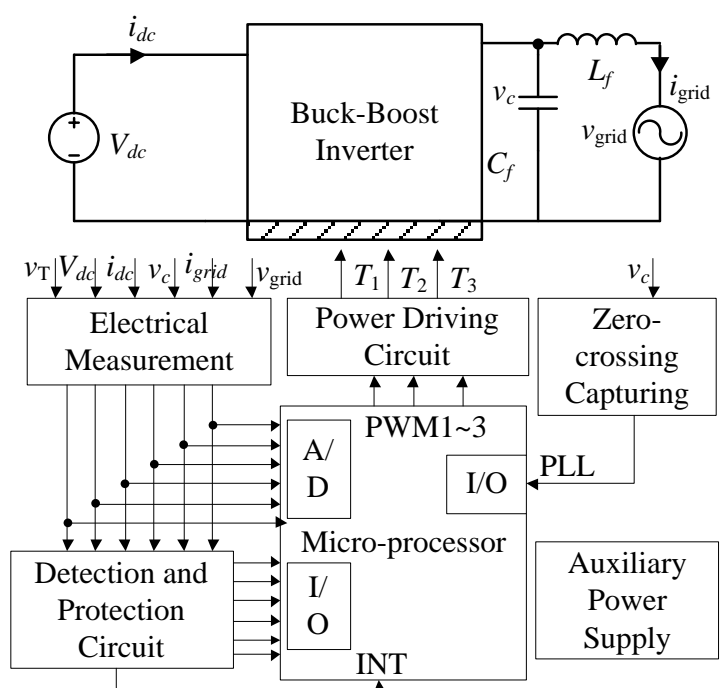

External Interrupt

Figure 4. Hardware Configuration of the Inverter

\section{Pulse Energy Modulation}

PEM signals for on/off control of power switches are generated by equating the energy demand for a sinusoidal grid current and change of energy stored in the fly-back inductor, in each switching period. The duty ratio of PEM signals for switch T1 (See Figure. ) is calculated according to the inverter energy demand based on instantaneous output power. If the switching frequency $F_{s}$ is $2 \mathrm{n}$ times the fundamental frequency of the grid voltage, one half cycle of the ac grid voltage can be divided into $n$ switching periods. For the kth switching period, the ac grid voltage can be expressed as:

$v_{\text {grid }}(k)=V_{P} \times \sin ((\pi / n) \times k)$

$V_{P}$ is the peak value of ac grid voltage. The injected current with a unity power factor can be described as:

$i_{\text {grid }}(k)=I_{M P} \times \sin ((\pi / n) \times k)$

where, $I_{M P}$ is the peak value of the injected current. The energy demand during the kth switching period for an inverter to inject into the grid is approximately equal to:

$E_{d m}(k)=I_{M P} \times V_{P} \times \sin ^{2}((\pi / n) \times k) \times T_{s}$

where, $T_{s}$ is the switching period, the variables are assumed to maintain constant values during a short switching period. The discharged energy in the fly-back inductor should be equal to the energy demand during each switching period. The fly-back inductor current during the $k$ th and $(k+1)$ th switching periods is shown in Figure 4 . Where, $i_{L}$ is the fly-back inductor current including $i_{L 1}$ and $i_{L 2}$. 


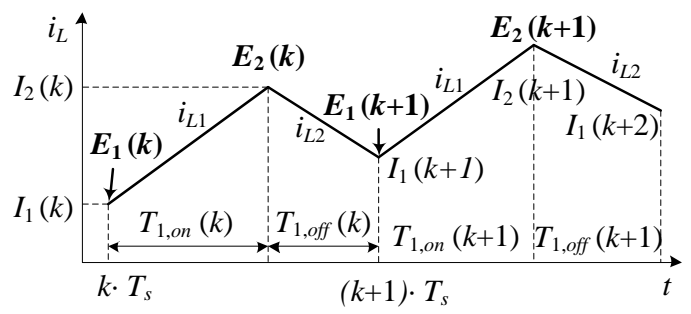

Figure 5. The Fly-Back Inductor Current in Charging and Discharging Periods in CCM

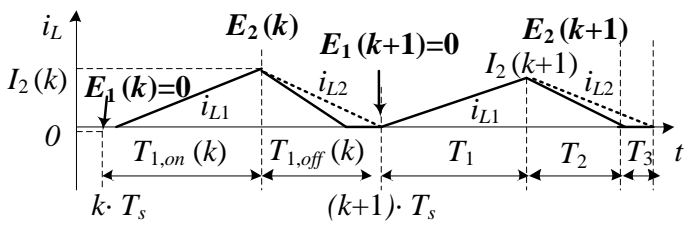

Figure 6. The Fly-Back Inductor Current During Charging and Discharging Periods in DCM

During the turn-on time $T_{o n}(k)$, the stored energy is charged from $E_{l}(k)$ to $E_{2}(k)$, and during the turn-off time $T_{\text {off }}(k)$, the stored energy is discharged from $E_{2}(k)$ to $E_{1}(k+1)$. Therefore,

$$
E_{d m}(k)=E_{2}(k)-E_{1}(k+1)=\frac{1}{2} L_{B B} \times\left(I_{2}^{2}(k)-I_{1}^{2}(k+1)\right)
$$

Based on the fly-back inductor currents at the beginning and ending of switching period (as $I_{l}(k), I_{l}(k+1), I_{l}(k+2)$ in Figure 4), this operation mode can be defined as CCM (i.e., continuous conduction mode). In the CCM as shown in Figure 4, the inductor current during a switching period never reaches zero. If the inductor current goes to zero during a switching period, DCM (i.e., discontinuous conduction mode) occurs, as shown in Figure 5.

\subsection{Discontinuous Conduction Mode}

In the DCM operation, the initial fly-back inductor current of each switching period is zero. Therefore, the initial energy stored in the inductor at the start of the each switching period is zero, as shown in Figure 5.

Peak current $I_{2}(k)$ can be calculated from dc input voltage and turn-on time of switch $\mathrm{T}_{1}$ as,

$$
I_{2}(k)=\frac{V_{d c} T_{o n}(k)}{L_{B B}}
$$

Inserting (8) into (7) with $I_{2}(k+1)=0$, (7) can be re-written as:

$$
E_{d m}(k)=\frac{1}{2} L_{B B} \times I_{2}^{2}(k)=\frac{1}{2 L_{B B}} V_{d c}^{2}\left(d_{-D C M}(k) T_{s}\right)^{2}
$$

Where, $d_{-D C M}(k)$ is the duty ratio in the kth switching period. Using (9) and (6) we can calculate the duty ratio in terms of the output current $i_{\text {grid }}$, the grid voltage $v_{\text {grid }}$, dc input voltage $V_{d c}$, switching period $T_{s}$ and fly-back inductance $L_{B B}$ for each switching period.

$$
\begin{aligned}
d_{-D C M}(k) & =\frac{1}{V_{d c}} \sqrt{\frac{2 \cdot I_{M P} \cdot V_{P} \cdot L_{B B}}{T_{s}}} \cdot \sin \left(\frac{\pi}{n} \cdot k\right) \\
& =D_{\text {max }_{-} D C M} \cdot \sin \left(\frac{\pi}{n} \cdot k\right)
\end{aligned}
$$

where maximum duty ratio $D_{\text {max_DCM }}$ is determined by $V_{d c}$ and $P_{o}$, as shown in (11). 
$D_{\text {max } \_D C M}=\frac{1}{V_{d c}} \sqrt{\frac{2 \cdot I_{M P} \cdot V_{P} \cdot L_{B B}}{T_{s}}}=\frac{2}{V_{d c}} \sqrt{\frac{P_{o} \cdot L_{B B}}{T_{s}}}$

The relationship between the peak current and the maximum duty ratio is expressed as (12):

$I_{M P}=\frac{D_{\max \_D C M}^{2} \cdot V_{d c}^{2} \cdot T_{s}}{4 \cdot V_{P} \cdot L_{B B}}$

Where, $I_{M P}$ can be governed by the Maximum Power Point Tracking (MPPT) algorithm according the dc input voltage. Through simulation studies, the required maximum modulation ratios for various dc input voltages are presented in Figure.6.

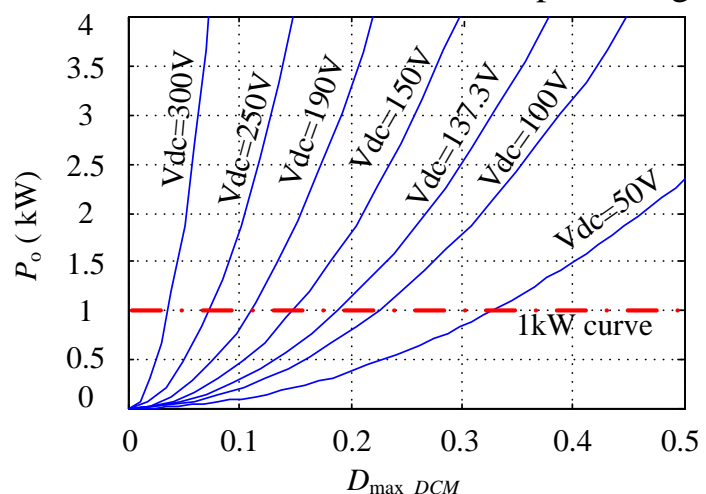

Figure7. Relationship between maximum duty ratio and output power for different dc input voltages when LBB $=300 \mu \mathrm{H}$ and $\mathrm{Ts}=1 / 12 \mathrm{~ms}$

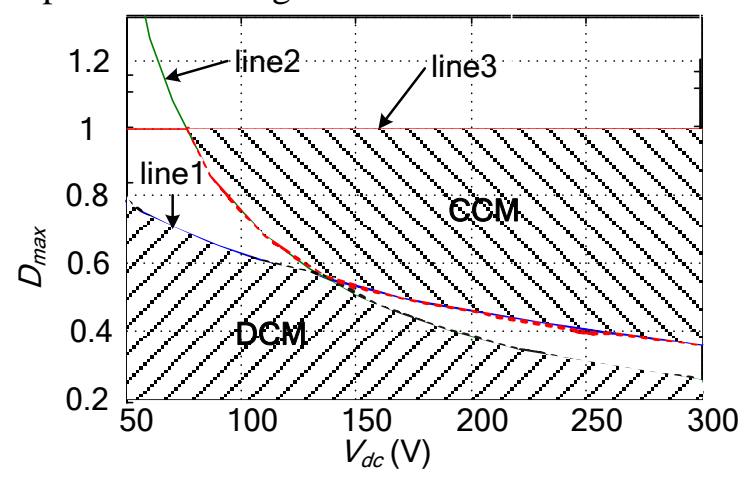

Figure8. Operation Area in the DCM and CCM ( LBB=300uH, Fs=12 kHz and $\mathrm{Po}=400 \mathrm{~W}$ )

\subsection{Continuous Conduction Mode}

To achieve CCM operation, fly-back inductance LBB should be increased to store more energy from the dc input source in one switching period according to (9). Part of the stored energy will remain in the fly-back inductor. Therefore it is important to measure the inductor current at the beginning of each charging and discharging period and calculate the additional energy required. During turn-on time Ton in the kth switching period, the fly-back inductor current increases from $I_{1}(k)$ to $I_{2}(k)$ :

$I_{2}(k)=I_{1}(k)+\frac{V_{d c} \cdot T_{o n}(k)}{L_{B B}}$

where $E_{1}(k), E_{l}(\mathrm{k}+1), E_{2}(k)$ and $E_{2}(k+1)$, as shown in Figure 4, are the stored energy in the fly-back inductor at different moments. The energy demand in the $k$ th switching period is

$E_{d m}(k)=E_{2}(k)-E_{1}(k)=\frac{1}{2} L_{B B} \times\left(I_{2}^{2}(k)-I_{1}^{2}(k)\right)$

Substituting $I_{2}(k)$ in (10) into (11) and solving for the duty ratio for CCM operation lead to: 
$d_{-} C C M(k)=\frac{L_{B B}}{T_{s} V_{d c}}\left(\sqrt{I_{1}(k)^{2}+\frac{2 E_{d m}(k)}{L_{B B}}}-I_{1}(k)\right)$

During turn-off time $T_{\text {off }}$, the inductor current decreases from $I_{2}(k)$ to $I_{1}(k+1)$ :

$I_{2}(k)=I_{1}(k+1)+\frac{V_{c}(k) \cdot T_{o f f}(k)}{L_{B B}}$

The relation between $I_{1}(k+1)$ and $I_{1}(k)$ can be obtained from (13) and (16):

$I_{1}(k+1)=I_{1}(k)+\frac{V_{d c} t_{o n}(k)}{L_{B B}}-\frac{V_{c}(k) t_{o f f}(k)}{L_{B B}}$

Therefore the initial inductor current $I_{1}(k)$ used to calculate $d_{-C C M}(k)$ can be predicted in the $(k-1)$ th switching period to avoid the time delays due to processor executions.

\subsection{Operation Area for DCM and CCM}

In the DCM operation, $I_{1}(k)$ and $I_{1}(k+1)$ is equal to zero. The time it takes for the fly-back inductor current to decrease to zero is no longer than the turn-off time Toff. Thus, the maximum duty ratio in the DCM is limited by:

$$
D_{\text {max } \_D C M} \leq \frac{V_{\text {grid } \_ \text {max }}}{V_{\text {grid } \_ \text {max }}+V_{d c}}
$$

From (15), the duty ratio in the CCM can be obtained:

$D_{\text {max } \_C C M}>\frac{2}{V_{d c}} \sqrt{\frac{P_{o} \cdot L_{B B}}{T_{s}}}$

(11), (18) and (19) along with $D_{\max }=1$ define the operation area (OA) of the inverter in the DCM and CCM , as illustrated in Figure 7, in which line1, line 2 and line 3 represent (18), (19) and $D_{\max }=1$.

\section{Design of Three-switch Fly-back Buck-Boost Inverter}

The design of a three-switch fly-back buck-boost inverter consists of software system design and hardware system design. Hardware design includes main power circuit, electrical measurement circuit, detection and protection circuit, control circuit, and auxiliary power supply etc., as shown in Figure 8.

\subsection{Hardware Design of Inverter System}

4.1.1. Power Circuit: This section introduces the design of the power components such as power diodes Dx $(x=1,2,3)$, switching devices $T x(x=1,2,3)$.

Following the analysis of Section II, the current ratings of switching devices and power diodes are selected as the peak of the fly-back inductor current. The voltage stresses of power diodes $v_{D 1}$ and switching devices $v_{T 2}$ can be express as following:

$v_{D 3}=v_{T 3}= \begin{cases}0, & \text { Mode } 1 / \text { Mode } 3 \\ V_{d c}-v_{c}, & \text { Mode } 2 \\ V_{d c}+v_{c}, & \text { Mode } 4\end{cases}$ 
where $V_{d c}$ is the dc input voltage, $v_{c}$ is the voltage of output capacitor $C_{f}$ and is also the output voltage of the inverter $v_{o}$. The polarity of $v_{c}$ and $V_{d c}$ is the same during Mode 2, and is opposite during Mode 4. The voltage stress of other power devices is:

$$
\begin{aligned}
& v_{D 2}=v_{T 2}= \begin{cases}V_{d c}+v_{c}, & \text { Mode } 1 / \text { Mode } 3 \\
2 v_{c}, & \text { Mode } 2 \\
0, & \text { Mode } 4\end{cases} \\
& v_{D 1}=v_{T 1}= \begin{cases}V_{d c}+v_{c}, & \text { Mode1 / Mode 3 } \\
0, & \text { Mode } 2 \\
2 v_{c}, & \text { Mde } 4\end{cases}
\end{aligned}
$$

The polarity of $v_{c}$ and $V_{d c}$ is the same during Mode1 and Mode 2, and is opposite during Mode 3 and Mode 4. Assuming $V_{d c}=50 \sim 300 \mathrm{~V}$ and the output voltage of the inverter is $120 \mathrm{~V} / 60 \mathrm{~Hz}$, then the maximum voltage stress of T3 and D3 is about $130 \mathrm{~V}$. The maximum voltage stress of $\mathrm{T} 2$ and $\mathrm{D} 2$ is about $470 \mathrm{~V}$, and the same as $\mathrm{T} 1$ and $\mathrm{D} 1$. The voltage rating of diodes and switching devices can be chosen as $500 \mathrm{~V}$.

4.1.2. Output capacitor $\boldsymbol{C} \boldsymbol{f}$ and filter inductor $\boldsymbol{L} \boldsymbol{f}$ : The size of the capacitor filter $\mathrm{C}_{\mathrm{f}}$ can be determined by equating the energy fluctuation in the capacitor with the energy delivered to the output in one switching period. If the average capacitor voltage is $\mathrm{v}_{\mathrm{c}}$ and the ripple of the capacitance voltage is $2 \Delta \mathrm{v}_{\mathrm{c}}$, the capacitance voltage fluctuates between $\mathrm{V}_{\mathrm{c}}+\Delta \mathrm{v}_{\mathrm{c}}$ and $\mathrm{V}_{\mathrm{c}}$ $-\Delta \mathrm{v}_{\mathrm{c}}$ as shown in Figure.3. Since the energy delivered to the output in one switching cycle is equivalent to the change of energy stored in the capacitor, as shown in (23).

$\frac{1}{2} C_{f}\left(\left(V_{c}+\Delta v_{c}\right)^{2}-\left(V_{c}-\Delta v_{c}\right)^{2}\right)=V_{P} I_{M P} T_{s}$

Simplifying (23) by equating $V_{c}=V_{P}$ and solving for the value of capacitance.

$C_{f}=\frac{I_{M P} T_{s}}{2 \Delta v_{c}}$

The capacitance determines the ripple voltage. For higher capacitance the ripple voltage will be minimized. In this case, setting $\Delta v_{c}=20 \mathrm{~V}, \mathrm{Ts}=1 / 12 \mathrm{~ms}$, then the output capacitor $C_{f}$ can be selected to about $10 \mu \mathrm{F}$.

The filter inductor $L_{f}$ filters the high frequency component of the output current caused by the switching action. Therefore the cut off frequency of the LC filter should be less than the switching frequency. The filter inductance can be calculated as

$$
L_{f}=\frac{1}{\left(2 \pi f_{c}\right)^{2} C_{f}}
$$

In this case, $f_{c}$ is designed to be about $1 \mathrm{kHz}$, so the $L_{f}$ can be obtained as $1 \mathrm{mH}$.

4.1.3. Fly-back Inductor: In order to reduce the size of the fly-back inductor, the inverter is designed for DCM operation. The fly-back inductor consists of two tightly coupled coils with equal inductances and turns, i.e., $\mathrm{L} 1=\mathrm{L} 2=\mathrm{LBB}$, and $\mathrm{N} 1=\mathrm{N} 2$.

The value of fly-back inductance is depended on the specifications of the application. According to the range of dc input voltage, rated power and DCM operation mode, the inductance L1 of primary inductor of fly-back transformer is chosen to be $300 \mathrm{uH}$ to limit 
the peak primary current $I_{p}$ for larger output power. $I_{p}$ is calculated from average current $I_{\text {avg }}$, ripple to peak current ratio $K_{R P}$, and maximum duty cycle $D_{\max }$

$I_{P}=I_{\text {avg }} \frac{2}{\left(2-K_{R P}\right) \cdot D_{\max }}$

Where, $I_{\text {avg }}$ is calculated from minimum dc input voltage, output power $P_{\mathrm{O}}$, and efficiency

$I_{\text {avg }}=\frac{P o}{\eta \cdot V_{\min }}$

Considering $D_{\max }=0.5, K_{R P}=0.7, P_{O}=400 \mathrm{~W}, V_{\min }=50 \mathrm{~V}$, and $\eta=90 \%, I_{p}$ can be obtained as around 28A.The turns of coil are $N_{1}=N_{2}=55$ and the wire size of the winding of coil is AWG11.

4.1.4. Control Circuit:The main function of the control circuit is PEM signal generation, electrical detection, and system protection. The control and protection function of the buck-boost inverter are provided by a low-cost, 16-bit 40MIPS DSP microprocessor (dsPIC33FJ64MC506). In this case, three different inputs (AN3, AN4, and AN5) are scanned in $\mathrm{CH} 0$, whereas AN0, AN1 and $\mathrm{AN} 2$ are the fixed inputs for $\mathrm{CH} 1, \mathrm{CH} 2$ and $\mathrm{CH} 3$, respectively. When any of the electrical signals are larger than the protection value, an over voltage or over current signal $\left(\mathrm{o}_{\mathrm{idc}}, \mathrm{o}_{\mathrm{io}}, \mathrm{o}_{\mathrm{Vdc}}, \mathrm{o}_{\mathrm{vc}}, \mathrm{o}_{\mathrm{vTe}} \mathrm{O}_{\mathrm{igrid}}\right)$ is read by I/O module to show the fault type. At the same time, the over-voltage or over-current signal is sent to interrupt module and DSP disables the PWM module. ZCD is the zero cross detecting signal and is captured by INT4 of interrupt module.

\subsection{Software Design of Buck-boost Inverter System}

The dsPIC33FJ64MC506 is programmed to capture the zero-crossing signals, sample six analog signals, execute over-voltage, over-current and over-temperature protection functions, and generate PEM signals. The operating time sequence of the control system is shown in Figure.10.

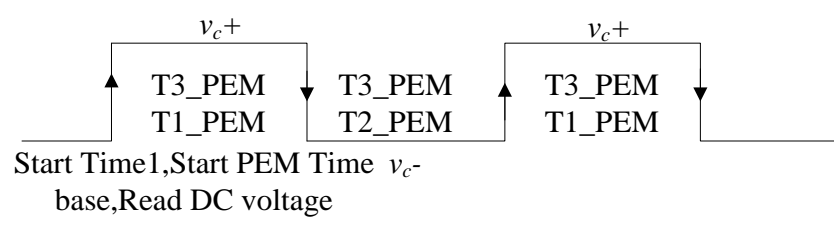
Figure 9. Operating Time Sequence of the
Control System

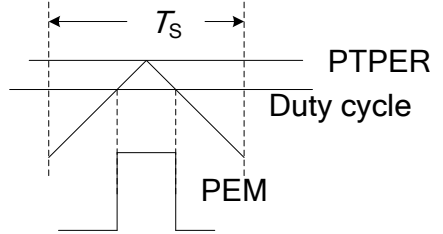

Figure10. Center-Aligned PEM Signals

The square wave signals produced by the zero-crossing detection (ZCD) circuit are connected to the Input Capture (IC) of the DSP microprocessor. The capture event, which is trigged on every rising and falling edge of ZCD signals, starts DSP Timer 1 and PWM time base. The interrupt service routine (ISR) sets up Time1 period register PR1. Capture ISR produces the PEM signals for switches $\mathrm{T} 1$ and $\mathrm{T} 3$ in the positive half interval of grid and generates the PEM signals for switches T2 and T3 in the negative half interval of grid.

Time1 ISR calculates the maximum duty ratio of PEM signals according to (6) and then calculates the duty ratio for every PEM signal according to a sine table. The center-aligned PEM signals of switches are produced by the DSP PWM module when the DSP PWM time base is configured in an up/down count mode shown in Figure 11. PTPER is DSP PWM time base period register and the switching frequency is equal to $12 \mathrm{kHz}$. PTPER is 
calculated according to the microprocessor clock period $T_{c y}$, the designed PEM period $T_{P E M}$ and the PTMR prescale value $S_{P T M R}$,

$T_{P E M}=\frac{2 T_{c y}(P T P E R+1)}{S_{P T M R}}$

In this paper, PEM frequency is $12 \mathrm{kHz}$, Microprocessor clock frequency is $40 \mathrm{MHz}$ and PTMR prescale value is equal to 1 . So, the value of PTPER can be calculated as

PTPER $=\frac{T_{P E M}}{2 T_{c y}}-1=1666$

In the Time3 ISR, the six analog inputs of voltage/current are sampled and converted to digital values.

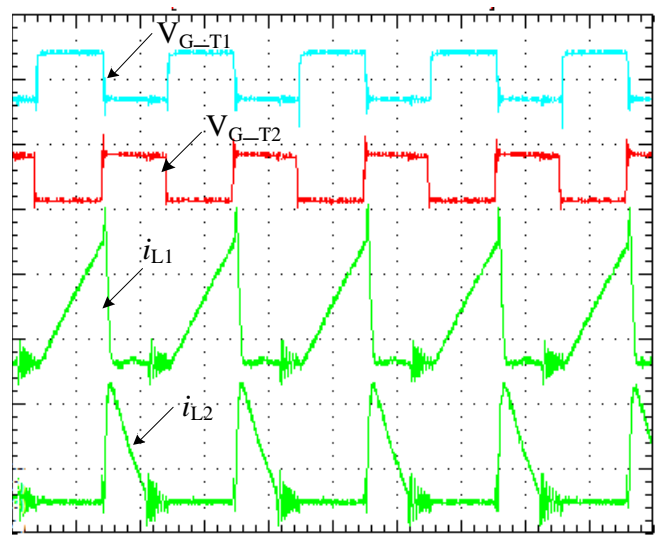

(a) During the positive half period Hardware configuration of the inverter.

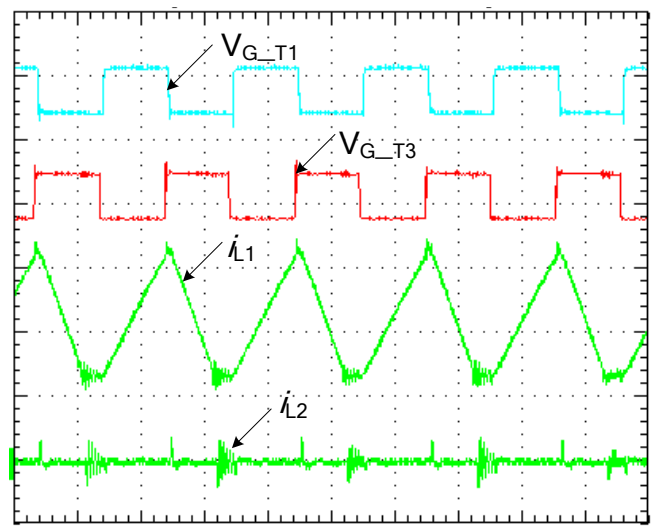

(b) During the negative half period

Figure 11. The Switching Signals of $T_{1}, T_{2}, T_{3}(20 \mathrm{~V} /$ div $)$ and Fly-Back Inductor Currents (5 A/div) $(40 \mu \mathrm{s} / \mathrm{div})$

\section{Experimental Results}

Based on the design of the hardware and software, a 400W, three-switch, fly-back, buck-boost, grid-connected inverter was developed. The fly-back inductance is $300 \mu \mathrm{H}$. Filter inductance $L_{f}$ and output capacitance $C_{f}$ are $1 \mathrm{mH}$ and $10 \mu \mathrm{F}$ respectively. The dc input voltage is variable from $50 \mathrm{~V}$ to $300 \mathrm{~V}$. An ac grid of $120 \mathrm{~V} / 60 \mathrm{~Hz}$ is connected with the buck-boost inverter. The switching signals for power switching devices are generated based on the proposed PEM principle at a switching frequency of $12 \mathrm{kHz}$. Experimental waveforms were measured by TDS3014C digital phosphor oscilloscope.

Figure 12 , shows the gate switching signals $\left(\mathrm{V}_{\mathrm{G}_{-} \mathrm{T} 1}, \mathrm{~V}_{\mathrm{G}_{-} \mathrm{T} 2}\right.$ and $\left.\mathrm{V}_{\mathrm{G}_{-} \mathrm{T} 3}\right)$, the fly-back primary inductor current $\left(i_{L 1}\right)$ and the secondary inductor current $\left(i_{L 2}\right)$. The dc input voltage $\left(V_{d c}\right)$ is $72 \mathrm{~V}$. The experimental results have demonstrated the charging and discharging process of the fly-back inductor during the positive and negative half periods of the output voltage. In the charging process, T1 turns on and $i_{L l}$ increases linearly at the rate of $V_{d c} / L_{B B}$. In the discharging process, $\mathrm{T} 2$ turns in the positive half period and T3 turns on in the negative half period, while $i_{L l}$ or $i_{L 2}$ decreases to zero at the rate of $v_{o} / L_{B B}$ and then holds to zero till the next switching period. 


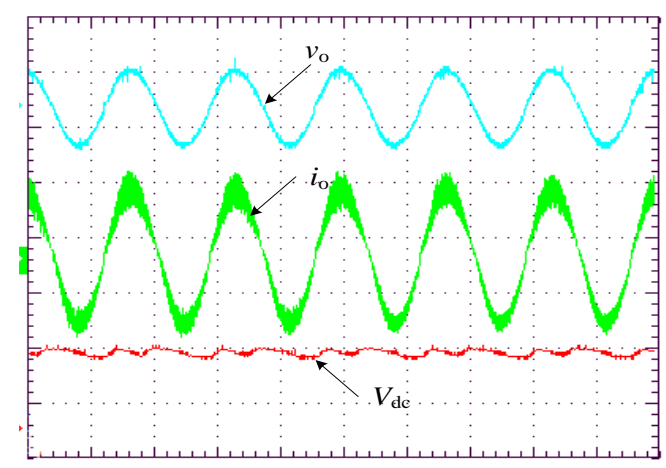

Figure 12. Waveforms of $v_{0}$ (200V/div), $i_{o}(2 \mathrm{~A} / \mathrm{div}), \mathrm{V}_{\mathrm{dc}}(100 \mathrm{~V} / \mathrm{div})$, (10ms/div)

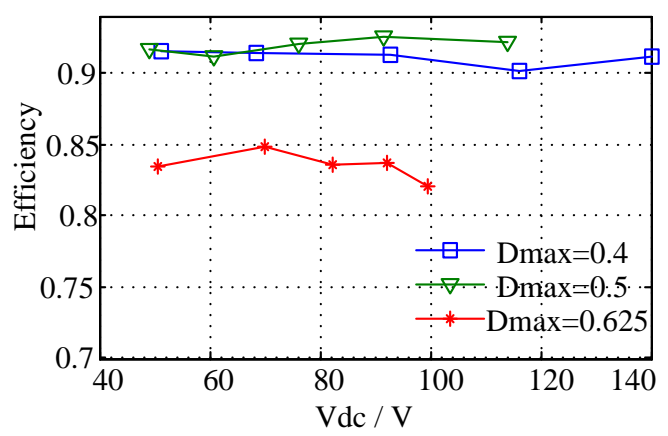

Figure 13. Measured Efficiency of the Inverter at Different Conditions

When the maximum duty ratio is 0.4 and the input dc voltage is $140 \mathrm{~V}$, the inverter waveforms under standalone operation with a $50 \Omega$ resistor load are showed in Figure 13. The root mean square (RMS) of output voltage is $99.9 \mathrm{~V}$ and the RMS of load current is 1.99A. The output power of inverter is $P_{o}=198.4 \mathrm{~W}$. The dc input power can be measured according to the duty ratio and input voltage at $P_{I}=217.78 \mathrm{~W}$, resulting in the efficiency of $91.1 \%$.

The efficiency of this buck-boost inverter was measured at the conditions of $D_{\max }=0.4$, 0.5 and 0.625 , at variable $V_{d c}$, as plotted in Figure.14. Experimental results show the efficiency of inverter decreases when the maximum duty ratio is larger than 0.5. The efficiency of inverter is higher than $90 \%$ when the maximum duty ratio is less than or equal to 0.5 .

Grid-connected operations of inverter have been tested on the experimental setup. Figure. 15 shows the input voltage, output capacitor voltage and injected grid current at $V_{d c}=75.28 \mathrm{~V}, D_{\max }=0.6$. The input power of inverter is $P_{I}=141.7 \mathrm{~W}$, output power is $\mathrm{Po}=$ $122 \mathrm{~W}$ and the efficiency of inverter is $86.12 \%$. Figure.16 shows the waveform of the ac grid voltage, grid current and output capacitor voltage. Experimental results show the phase shift between the grid voltage and the grid current is almost zero, i.e. a unity power factor.

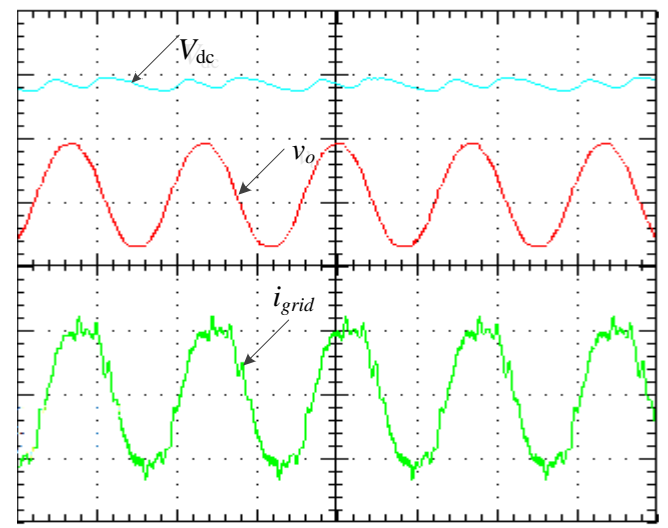

Figure14. $\mathrm{V}_{\mathrm{dc}}(100 \mathrm{~V} / \mathrm{div}), \mathrm{v}_{\mathrm{o}}(100 \mathrm{~V} / \mathrm{div})$, $\mathrm{i}_{\text {ogrid }}(2 \mathrm{~A} / \mathrm{div})(10 \mathrm{~ms} / \mathrm{div})$ with $\mathrm{V}_{\mathrm{dc}}=72 \mathrm{~V}$ and $D_{\max }=0.6$

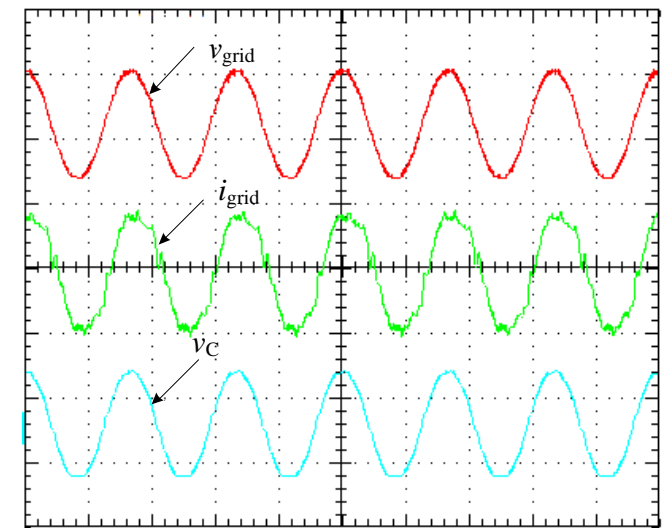

Figure15. $v_{\text {grid }}(200 \mathrm{~V} / \mathrm{div})$, $\mathrm{i}_{\text {grid }}(1 \mathrm{~A} / \mathrm{div})$, $\mathrm{V}_{\mathrm{o}}(200 \mathrm{~V} / \mathrm{div})(10 \mathrm{~ms} / \mathrm{div})$ with $\mathrm{V}_{\mathrm{dc}}=100 \mathrm{~V}$ and $D_{\max }=0.6$ 


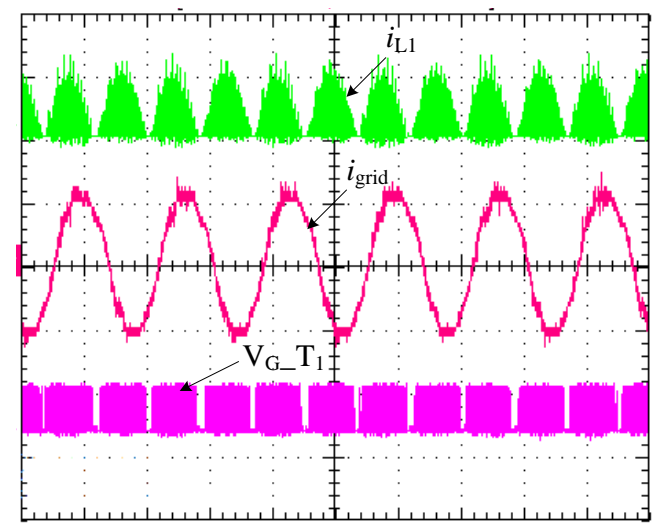

Figure 16. $\mathrm{i}_{\mathrm{L} 1}(1 \mathrm{~A} / \mathrm{div}), \mathrm{i}_{\text {grid }}(1 \mathrm{~A} / \mathrm{div}), \mathrm{V}_{\mathrm{G}_{-}} \mathrm{T} 1 \mathrm{(}(15 \mathrm{~V} / \mathrm{div})(10 \mathrm{~ms} / \mathrm{div})$ for

The duty ratio was determined based on the dc input voltage and output reference current according to the PEM algorithm proposed in this paper. Figure 17, shows grid current, the fly-back inductor current and PEM signals when the output reference current is $1 \mathrm{~A}$ at peak. The duty ratio is automatically adjusted in the control software when the dc input voltage is changed. The measured ac current peak value is 1.04A. The experimental results have verified the operation of the proposed buck-boost inverter and PEM technology for grid-connected DG systems.

\section{Conclusion}

The authors have proposed an innovative three-switch fly-back buck-boost inverter for small DG applications, and a new pulse energy modulation method for generating switching signals for the inverter control. This inverter provides a potential solution for a low cost and high efficiency dc-ac converter. It has a low component count with only three switches and can accommodate a wide range of dc input voltage for an improved energy output from variable DG resources. Only one switch operates at any moment, leading to a high efficiency.

This paper presents the concept of pulse energy modulation (PEM), as a new modulation method alternative to commonly used PWM and PFM. The PEM principle was applied to the three-switch buck-boost inverter in the DCM operation and CCM operation. The duty ratio of PEM signals is variable with the dc input voltage and ac output power demands. In DCM operation, the stored energy in the fly-back inductor is fully transferred to the grid and the duty ratio is variable with sine wave when the dc input voltage is constant. In CCM operation, the duty ratio is more complicated because the stored energy is transferred partly to the grid.

The hardware and software design of the inverter was conducted for the inverter. The fly-back inductor for a $400 \mathrm{~W}$ inverter was designed according to DCM operation to achieve a compact design. The control system was implemented with DSP dsPIC33FJ64MC506. The analogy-to-digital conversion, zero-crossing capture, PEM signals generation and control process of DSP were presented in the paper.

The experimental results have shown that pulse energy modulation provides the buck-boost inverter with a new strategy to inject a sinusoidal current into the grid under various input conditions. The efficiency of inverter is higher than $90 \%$ when the maximum duty ratio is no larger than 0.5 . 


\section{Acknowledgments}

This work is supported by Science and Technology Industrial Planning Project of Jiangxi Province, China (20151BBE50118); and by National Natural Science Foundation of China (51467006); and by the Education Department of Jiangxi Province (GJJ14387).

\section{References}

[1] E. Koutroulis and F. Blaabjerg, "Design optimization of grid-connected PV inverters. The Twenty-Sixth Annual IEEE Applied Power Electronics Conference and Exposition (APEC)", Fort Worth, TX, USA, March 6-11, vol. 1, no. 2, (2011), pp. 91-698.

[2] Z. Yao, L. Xiao and Y. Yan, "Seamless Transfer of Single-Phase Grid-Interactive Inverters Between Grid-Connected and Stand-Alone Modes", IEEE Trans. Power Electron., vol. 25, no. 6, (2010) JuneNovember, pp. 1597-1603.

[3] M. Kusakawa, H. Nagayoshi, K. Kamisako and K. Kurokawa, "Further improvement of a transformerless, voltage-boosting inverter for ac modules", Solar Energy Mater. Solar Cells, vol. 67, (2001) March, pp. 379-387.

[4] B.V. Prasad, S. Jain and V. Agarwal, "A Universal Single-Stage Grid-Connected Inverter", IEEE Transactions on Energy Conversion, vol. 23, no. 1, (2008) March, pp. 128-137.

[5] H. Patel and V. Agarwa, "A Single-Stage Single-Phase Transformer-Less Doubly Grounded GridConnected PV Interface", IEEE Transactions on Energy Conversion, vol. 24, no. 1, March (2009), pp .93-101.

[6] S. B. Kær and F. Blaabjerg, "A novel single-stage inverter for the ac-module with reduced low-frequency ripple penetration", The 10th EPE European Conf. Power Electronics and Applications, Toulouse, France, CDROM, (2003) September 2-4.

[7] N. Kasa and T. Iida, "Flyback type inverter for small scale photovoltaic power system", IEEE IECON 2002, Seville, Spain, vol. 2, (2002) November 5-8 pp. 1089-1094.

[8] L. Chang, Z. Liu, Y. Xue and Z. Guo, "A Novel Buck-boost Inverter for Photovoltaic Systems", 31st Annual Conference of the Solar Energy Society of Canada, Montreal, Canada, (2006), August 20-24.

[9] Chang and Z. Liu, "Single-Phase Buck-Boost Inverter", US Patent 7,333,349, (2008) February.

[10] B. S. Nakaoka, S. P. Mun, T. Mishima and S. K. Kwon, "Pulse Width and Pulse Frequency Modulation Pattern Controlled Active Clamp ZVS Inverter Link AC-DC Power Converter Utility AC Side Active Power Filtering Function for Consumer Magnetron Driver", IEEE Proc. IECON2007, Taipei, China,, (2007) November 5-8, pp.1968-1971.

[11] Z. Liu, "Study of Single-Phase Single-Stage Buck-Boost Inverters", University of New Brunswick, M.Sc. Thesis, (2004) August.

[12] X. Mao, R. Ayyanar and H. K. Krishnamurthy, "Optimal Variable Switching Frequency Scheme for Reducing Switching Loss in Single-Phase Inverters Based on Time-Domain Ripple Analysis", IEEE Transactions on Power Electronics, vol. 24, no. 4, (2009) April.

[13] X. Dai and Q. Chao, "The research of photovoltaic grid-connected inverter based on adaptive current hysteresis band control scheme", in 2009 International Conference on Sustainable Power Generation and Supply, Nanjing, China, (2009) April 6-7, pp. 1-8.

[14] H. Kim, M. Falahi, T. M. Jahns and M. W. Degner, "Inductor Current Measurement and Regulation Using a Single DC Link Current Sensor for Interleaved DC-DC Converters. IEEE Trans. on Power Electron., vol. 26, no. 5, (2011) May, pp. 1503-1510.

[15] H. Zhang and T. Meng, "A Novel Single-Phase Power Factor Corrector with One Cycle Control Technology”, in the Second International Conference on Intelligent Computation Technology and Automation, ICICTA '09, Changsha, Hunan, China, vol. 2, (2009) October 10-11, pp. 961 - 964.

[16] T. Hirao, T. Shimizu, M. Ishikawa and K. Yasui, "A modified modulation control of a single-phase inverter with enhanced power decoupling for a photovoltaic AC module", 2005 European Conference on Power Electronics and Applications, Dresden, Germany, (2005) January, pp.132-141.

[17] S. Jain and V. Agarwa, "A Single-Stage Grid Connected Inverter Topology for Solar PV Systems With Maximum Power Point Tracking”, IEEE Transactions on Power Electronics, vol. 22, no. 5, (2007) September, pp.1928-1940.

[18] A. T. Woldegiorgis, Y. Zhang and L. Chang, "Pulse Energy Modulation of a buck-boost inverter Energy Conversion Congress and Exposition (ECCE)”, 2011 IEEE, (2011) 17-22 September, pp. 2001-2006. 


\section{Author}

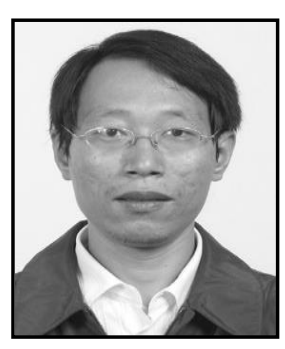

Yonggao ZHANG, born in 1975, associated professor; his current research interests include distributed generation, micro-inverter, etc., 
International Journal of Grid and Distributed Computing Vol. 9, No. 10 (2016) 